\title{
Gide's Reflections on Human Dilemmas in The Pastoral Symphony
}

\author{
Yuan-zhen Peng \\ English Department, North China Electric Power University, Baoding, Hebei, PRC
}

\begin{abstract}
This paper makes a detailed analysis of Gide's works The Pastoral Symphony in order to expose the underlying paradoxes in the characters' inward world due to religious and moral restraints. It is appropriate to write in the form of diaries in uncovering the characters' inner feelings and desires.
\end{abstract}

Keywords—paradoxes, religion, morality, love

\section{从纪德的《田园交响曲》看人之困境}

\author{
彭园珍
}

华北电力大学英语系, 保定, 河北, 中国

\begin{abstract}
摘 要 本文通过对纪德的作品《田园交响曲》进行文本分析, 从而揭示人物复杂的内心世界里充满了宗教伦理道德与人类欲望 的矛盾斗争。人为了追求幸福, 企图冲破禁忌, 然而最终导致了个人命运和感情的悲剧结局。

关键词 矛盾, 宗教, 道德, 爱情
\end{abstract}

\section{1. 引言}

安德烈·纪德（1869-1951），法国作家，1947 年获得诺 贝尔文学奖, 是因其“内容广博和艺术意味深长的作品 --这些作品以对其真理的大无畏的热爱, 以锐敏的心理洞察 力表现了人类的问题与处境”。纪德受家庭宗教教育的影 响, 对《圣经》、福音书文本学习后产生浓烈的喜爱之情。 他的日记体小说《田园交响曲》创作于 1919 年, 讲述了一 名乡村牧师收养盲女热特律德的由来。作品通俗易懂, 采 用了散文诗一样抒情的语言风格, 把故事情节和人的内心 斗争按照时间或者说按照事情发生的本来顺序一一娓娓道 来。平静的田园式的散文渐渐发展成了一首人物内心斗争 激烈交响曲。

故事中, 牧师想尽各种办法让热特律德接受教育, 盲 女因此变得聪慧, 牧师爱上了盲女, 由于牧师的妻子阿梅 莉对热特律德的冷淡态度, 牧师把盲女安排到小教堂继续 学习, 热特律德进步非常快, 牧师抽空和她一起散步聊天, 享受着这阿梅莉无法给与的宁静。牧师请来医生为热特律 德治病, 热特律德眼睛能看见之后来到牧师家, 阿梅莉脸 上的痛苦表情让她有罪恶感, 并且发现自己爱的是牧师的 大儿子雅克并非牧师, 于是借出去采花为由跳河自尽了。
读者没有预料到的悲剧结局, 盲女本可以因为能看到外面 的世界而过上幸福的生活, 是什么让她选择了结束自己年 轻的生命? “我已有打算, 要记述这颗虔诚的灵魂成长的 全过程。我只想让她崇拜和热爱上帝, 才把她带出了黑夜。 感谢主交给我这种使命。” (纪德, P91) 是热特律德在牧 师家或者说小教堂所受的宗教教育让她觉得应该受到谴责 吗? 那盲女和盲女的爱是否应该受到谴责呢? 这种结局是 否又是对宗教对道德的非人性化的谴责? 本文旨在分析人 的内心矛盾冲突以揭示出宗教伦理道德对人的限制, 给人 造成了进退两难的境地。

\section{2. 宗教束缚}

田园般的散文写法让故事从一开始充满了宁静和安 详, 一切都那么美丽和善良, 此时的 “上帝” 是仁慈的, 善 良的。“.....五年未见, 也说不准小湖在什么方位, 忽 见它披着彩霞, 映现美妙的夕照, 还真恍若是在梦中见过。” （纪德, P92）“只见山坡上一间茅舍, 若不是升起一缕炊 烟, 真好像没有人住。那缕细细的炊烟, 在暮色昏沉中蓝 幽幽的, 升到金霞的天空里又染成金黄色。”(纪德, P92) “我忽然憬悟到, 上帝将一种职责摆在我的面前, 我若是躲 
避就难免怯懦了。”（纪德，P93）牧师按照“上帝”的旨意 义不容辞的收留了这个可怜的孤儿。牧师感到了责任和使 命, 应该帮助这个可怜的孩子。纪德把散文式的语言用在 小说中, 读来优美舒畅, 作为一个牧师自己写的日记, 这 符合牧师的身份和他超脱世俗、都市喧闹的心态。当下, 牧师决定把盲女带走, 带回家, 在他看来, 盲女没有意识, 因为她脸上毫无表情, 是“一堆无意识的肉体, 随便让人带 走” (纪德, P94)。因为是日记, 所以作者能利用这种形式 记录下牧师的真实想法。此时牧师的内心感受是想用爱心 把盲女带向光明的世界。“主啊! 这颗灵魂, 贝在这不透明 的躯体里, 无疑在等待您的恩惠之光照到它。” (纪德, P94) 牧师的职责就是履行“上帝”赋予的职责和使命, 这时, 宗 教的教导与牧师内心的想法是一致的, 不存在矛盾, 不存 在对宗教和“上帝”的质疑。

日记体的形式明显是因为纪德想真实地记录事情的来 龙去脉和主人翁毫无保留的真实的想法和感受, 作者无疑 是要勇敢的展示真实的生活和真实的人或者说真实的内心 世界。“我特别注重真实, 不能避而不谈我回到家要遭受的 灾难。”(纪德, P94) 带着盲女回到家, 就像牧师推测的 那样, 他的妻子对他爱管闲事的习惯颇有微词。牧师没有 看到热特律德的变化和进步之前, 对阿梅莉的态度是持理 解和宽容的态度, 因为牧师肯定了一点, 即阿梅莉是个善 良的女人。“我妻子还是上手帮忙了, 须知她最自然的举动 总是最好的举动; 不过, 她的理智不断抗争, 往往战胜感 情。” (纪德, P95) “最自然的举动总是最好的举动”, 纪 德在此处已埋下伏笔, 作者的观点已经悄无声息地在此处 冒出端倪。纪德赞成感情的自然流露, 追求人最自然的行 动, 即发自内心的欲望和想法, 而不是理智战胜感情, 相 反, 纪德推崇人按照心灵的牵引去爱。这种几乎纵欲的思 想与牧师的宗教信仰之间应该是格格不入的。那作者想通 过描写这种矛盾的行为和思想来反映和揭露什么呢?

先来看看牧师对盲女热特律德的情感前后有什么变 化。首先他收养她的时候肯定是出于同情, 是善良的举 动。“但是我出于天性, 又基于道德原则, 一贯这样行事, 根本不算计我一时冲动会增加多少开销 (我始终认为, 计较花费违背福音书)。” (纪德, P99) 他因为妻子对盲 女的歧视而反感, 但是还是认为妻子为他的诸多善行付 出了很多, 并恳请她这次也能帮助照顾热特律德。盲女 身上的肮脏惹恼了阿梅莉, 其实也让牧师觉得恶心, 但 是作为牧师, 他又觉得有责任履行“上帝”的意愿。牧师 的善行让周围人信任他, 把他当成好人。那牧师对待自 己的家人或孩子又是什么样的态度呢? “大人以为他们 性情温柔, 其实他们甜言蜜语, 只想得到爱抚。” (纪德, P99）这里的“他们”是指牧师的孩子们。天真可爱的孩子
在牧师的心里是这么自私, 可见牧师的心灵也并不完全 美好, 他的自我表白恰恰印证了他本人的自私, 他没有 以宽容博爱的心来对待自己身边的孩子, 所以他眼里的 孩子才会是自私的, 孩子越大跟他越疏远是有原因的, 因为他已经不爱家里的孩子们了, 除非孩子们按照他的 意志去做事情。比如热特律德的问题, 牧师觉得他的妻 子和孩子们都应该帮他照顾和善待盲女, 不管愿不愿意。 这是给盲女施与“上帝”的恩惠。那除了家人, 牧师是不 是对他人会有无私的爱呢?

暂时回到牧师对盲女的态度这个问题上来。牧师对盲 女施教十几天, 毫无起色, 盲女的愚针让牧师心生厌恶之 情, 甚至后悔当时把她带回家, 所以已经表明牧师的关爱 并不是彻底的无私。阿梅莉却因为牧师对盲女的冷淡对盲 女越加照料。阿梅莉的嫉妒的确是牧师帮助盲女脱离愚昧 无知状态的一大阻力和障碍。这是婚姻家庭给人造成的限 制和束缚。

牧师接受朋友马丹的建议, 改变了教育方法, 多让热 特律德靠感觉来学习。马丹比较悲观, 认为人的五官感觉 给人增添了不少烦恼和罪恶, 牧师不赞成, 欣然同意执行 这种方法。牧师对盲女施教的投入, 阿梅莉显然是不屑一 顾的, 而盲女的进步让牧师安慰。热特律德的快速进步和 对诗歌音乐的领悟力让牧师爱上了这个心灵纯洁干净的少 女, 对自己的妻子抱怨随之越来越多。当发现自己的大儿 子雅克偷偷去教堂找热特律德教她弹琴的时候, 牧师找大 儿子谈话让他离开热特律德, 认为雅克是在欺负一个不懂 世事的纯洁姑娘。牧师的虚伪立刻暴露无遗, 牧师可以爱 热特律德, 却要拆散她和雅克两个年轻人, 理由是要保护 热特律德的纯洁。结果被活活拆散的一对年轻人该宗信了 天主教, 雅克成了天主教神职人员, 热特律德最后也忍受 不了痛苦而结束了自己年轻的生命。牧师显然是要完全占 有热特律德的世界, 包括她的思想和感情, 多么自私的欲 望。宗教信条让步于牧师心中不断滋生的欲望, 他对妻子 阿梅莉的一切行为都觉得难以容忍, 心中渴求着受着诗歌 和音乐熏陶的热特律德。这恰恰是纪德个人的真实写照, 纪德从小在家里接受严格的宗教教育, 尤其是来自母亲的 严格要求。由于长期受到束缚, 纪德一方面自身有了根深 蒂固的宗教信仰, 一方面又主张人应按照内心的想法或欲 望行事, 大胆张扬着喜新厌旧的自然心态。“真诚, 对纪德 来说, 并非只是率真, 它更多在于不向自我隐瞒任何东西, 即使有些私密的暴露显得是丑闻, 要毫不畏惧地揭示人阴 暗褶皱中深藏的自我。” (宋敏生、张新木, 2010) 纪德采 用的日记体无非是想把一个人的一切内心的秘密公诸于 众, 纪德用艺术向世人宣告: 这就是人。伪善成了牧师作 为男人真实的一面。纪德没有采取枯燥的说教方式, 告诉 
读者应该听从宗教信条的指导, 还是应该完全抛弃宗教, 去追求自己渴求的幸福, 只是原原本本地把牧师的心理变 化逐渐地像《田园交响曲》那样慢慢演奏出来, 在平静美 好的生活中大胆探索人性的恶。“一个伪君子的真面目至此 完全祄托出来。”（郑克鲁，1997）

\section{3. 家庭伦理}

《田园交响曲》这个故事发生在牧师家里, 涉及牧师 的妻子和儿子, 妻子痴妒盲女热特律德, 因为牧师给予她 的关心和在身上花费的时间和精力, 儿子雅克没有嫌弃热 特律德, 主动抽时间教她音乐并对她宣讲新教的教义。在 牧师几乎想放弃教育盲女的时候, 阿梅利却欣然接受照顾 盲女的任务。作为五个孩子的母亲, 阿梅莉辛勤劳作, 生 活疲急是肯定的现实。牧师忙于外面的事务, 家里的劳动 任务很少分担。纪德没有把阿梅莉刻画成一个圣女, 在家 任劳任怨, 对于牧师的工作不叫思索地支持和推崇。纪德 采用的现实主义写法, 阿梅莉尽着做妻子和母亲的责任和 义务, 当看到牧师把时间和精力放在热特律德身上时, 䃚 妒的炉火控制了她的情绪, 就像牧师的欲望控制着他的行 为一样。阿梅莉的世俗让牧师心生厌恶, “萨拉酷似她母亲, 因此, 我很想把她送进寄宿学校。因为, 我在萨拉身上只 发现世俗的兴趣: 她效仿母亲, 只关心平庸琐事, 脸上没 有什么表情, 仿佛僵化了, 显露不出一点心灵的火焰。对 诗歌毫无兴趣, 连书也不看; 什么时候撞见她们娘俩, 我 也没有听到我希望参与讨论的话题。我在她们身边, 只能 更痛苦地感到我是多么孤独, 还不如退回我的书房, 我也 逐渐养成了这种习惯。” (纪德, P138-139) 牧师在家里感 到了世俗的窒息感, 回到书房, 回到自己的世界, 以逃避 家庭生活。“每次回到名为“谷仓”的温暖氛围中, 我感觉是 多好的休息、多大的安慰啊; 假如一连两三天没有去, 我 又觉得是多大的损失啊! ”(纪德, P139) 谷仓有热特律德, 她在那成了三个盲女的老师, 教她们认字和做各种小活儿。 牧师对于谷仓却是心驰神往, 因为那里充满了温情和爱, 没有任何世俗的要求和噪音。这是牧师逃避生活的借口 吗? 这是真实的现实, 牧师真实的心理状态, 无论它是 否符合人情道德。妻子在家操持家务, 做丈夫的忙完了 外面的事情, 回到家里, 按理应该互相交流一天的忙碌 情况, 分享快乐, 分担压力和痛苦, 这是理想美好的状 态, 也是盲女在看不见这个世界时的一种状态。试想, 牧师和阿梅莉最初是不是能够达到这种你痛我也痛, 你 忧我也忧, 你快乐我也快乐的状态呢? 我们想象中应该 是。怀着美好的愿望我们组建了家庭。繁重的家务让阿 梅莉唠唠叨叨, 心胸也变得狭小, 除了世俗的事务无㗇顾 及其他。她为家庭作出了巨大贡献, 牧师本来应该除了感
恩之外别无其他奢求。可是现实不是, 家庭的伦理道德变 得似有似无。相比宗教信条的束缚, 家庭的伦理道德更加 容易冲破。“迄今为止, 她看不见我而一直爱我, 可是想想 她要看见我了, 这个念头令我坐立不安, 简直难以忍受。 她会认出我来吗? 有生以来, 我头一回对着镜子惴惴不 安地询问。假如我感觉出她的眼睛不如她的心宽容, 那 么深情, 我该怎么办呢? .......热特律德应当明天回来。 这一周, 阿梅莉只向我表现她性情最好的方面, 似乎有 意让我忘掉去住院的姑娘, 并和孩子一道准备庆贺她出 院归来。”(纪德，P145-146）阿梅莉在期望牧师忘了热 特律德, 牧师内心却极其惦记着小姑娘是否会依然爱她。 阿梅莉深情地注视着牧师, 牧师却尧首以盼热特律德的 归来。家庭和义务已经退位给爱情, 变成了颜色淡淡的 背景图。在故事的结局, 热特律德安眠之后, 牧师觉得 自己的爱情之水彻底干涸。“我多想痛哭一场, 然而我觉 得, 这颗心比沙漠还要干燥。”(纪德, P152)

相比而言, 家庭伦理道德对牧师的大儿子雅克有决 定性的影响。父亲的话可以辩驳, 爱情只能留在心中。 “我爱热特律德, 也敬重她, 跟您这么说吧, 我爱她和 敬重她的程度是一样的。我同您的想法一样, 扰乱她的 心灵, 欺她单纯无知, 欺她双目失明, 是卑鄙可耻的。”

（纪德, P120）牧师以家长的身份迫使雅克从热特律德 身边离开了, 阻止了两位年轻人的婚事。雅克的爱情迫 于家庭伦理的压力被窒息而死。

\section{4. 盲女的死}

盲女从肮脏、愚针到聪慧、宽容是一件令人兴奋的事 情。没有哪一个盲人不渴望见到光明。可是结局恰恰是我 们没有料到的, 热特律德选择了离开这个世界。原因是什 么呢? 先来看牧师的朋友马丹在给牧师提供教授热特律 德的“感受法”时说的一段话。“我只是想说明，人的灵魂 更容易, 也更愿意想象美好、悠然自在与和谐, 而不去 想象把人世高的乌烟瘴气、百孔千疮的放荡和罪恶。正 是这五种感官向我们提供情况, 有助于我们放荡和作恶。 因此我认为, 维吉尔的话 “自知其善”不如改为 ‘不知其 恶”, 而 ‘其乐无穷’, 这就教导我们: 世人若是不知道罪 恶, 那该有多幸福啊! ”（纪德, P103）小说中反复出现 过“你们若是盲女, 世间就没有罪恶了。”热特律德什么 都看不见的时候, 想象的一切事物都是美好的, 包括大 自然的景色，包括人的情感。这个阶段的热特律德就像 一个懵懂的孩童, 尚未触碰到社会的复杂和人性的罪恶。 见到这个世界后, 她看到了阿梅莉痛苦的表情, 发现自 己不爱牧师, 爱的是雅克, 她的心容不下自己的罪恶, 容不下时间的丑恶。一颗孩童般纯真的心灵遭受到了毁 
灭性的打击, 她太稚嫩了, 太脆弱了。所以说盲女渴望 见到的光明底下是人间的痛苦和不幸。马丹的话被应验了, 盲女象征着那天真无邪的孩童。

\section{5. 结语}

真实的生活和人性在纪德的笔下展露无遗, 似乎只要 成为纪德描写的人物, 纪德就把他或她置于矛盾体中。牧 师、阿梅莉、热特律德和雅克, 都面临着人生的矛盾。人 的内心世界颇不平静, 道德与欲望的斗争从未停止过。

\section{参考文献(References)}

[1] André Gide, The Pastoral Symphony, trans. by Li Yumin, Shanghai: Shanghai Translation Publishing House, 2011.

[2] Liu Ke, “André Gide's critical reflection on Christianity in Straight is the Gate and The Vatican Cellars," in Foreign Literatures, 2006 (3), pp.75-86.

[3] Song Minsheng, Zhang Xinmu, “Art as commitment: André Gide's writing of the self," in Contemporary Foreign Literature, 2010(4), pp.16-23. 